A s i a $\mathrm{n}$ J o u r n a l of

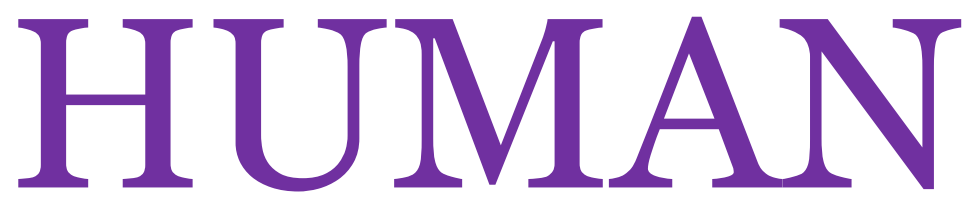

Printed 2017.0430 ISSN2188-059X

Published by Asian Society of Human Services
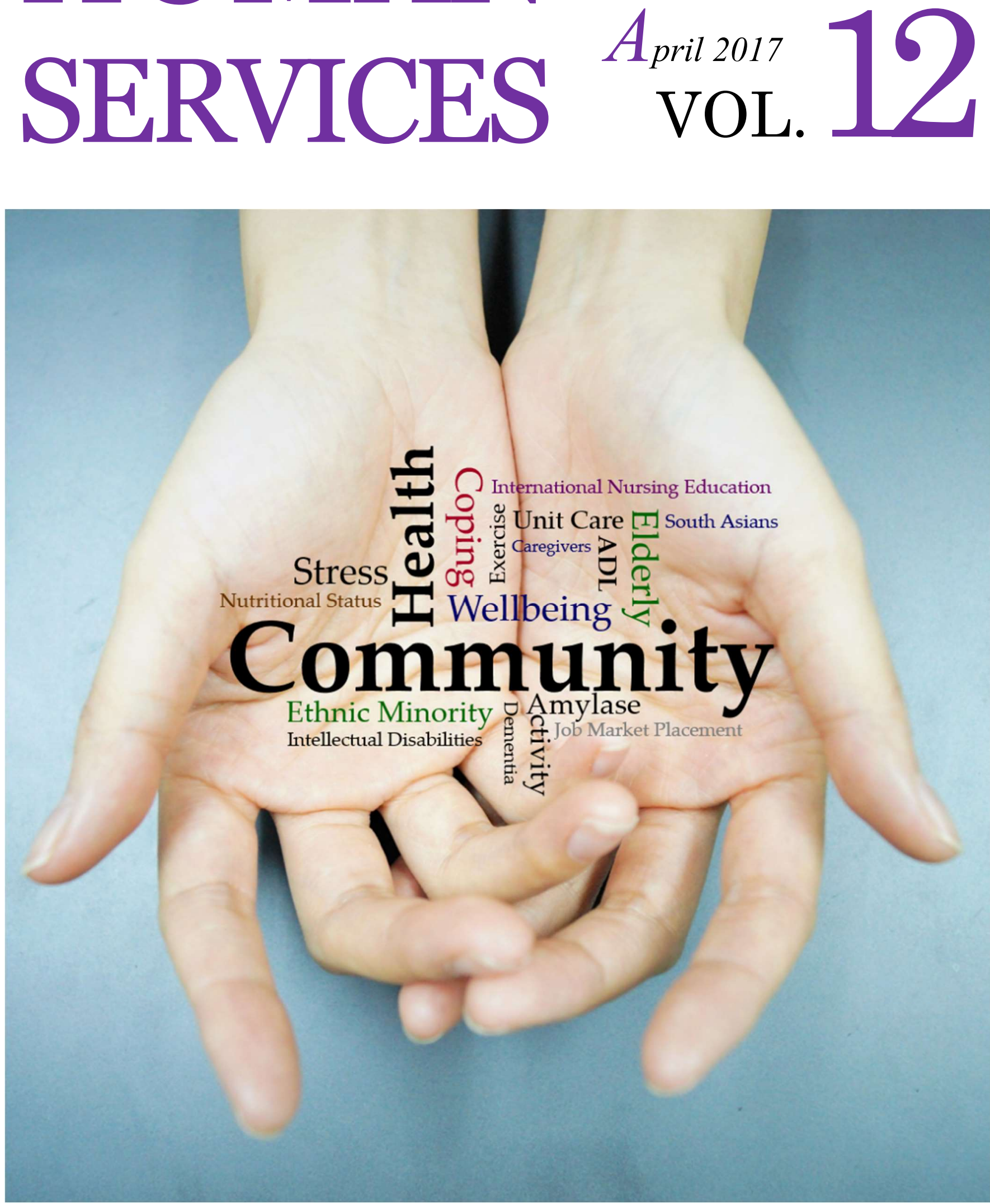


\title{
Associations among the Nutritional Status and Mental/Physical Functions of Care-dependent Individuals Living in Residential Homes for the Elderly
}

\author{
Yuko FUJIO Hiromi SHIMADA Tomoko SUGIYAMA Nobuhiro SATO \\ Department of Gerontology, Juntendo University, Japan
}

\begin{abstract}
This study examined the nutritional status and mental/physical functions of care-dependent individuals living in residential homes for the elderly, focusing on malnutrition as a leading cause of the progression of care dependency, to clarify the associations among them. A status survey was conducted, involving 147 care-dependent individuals living in 3 residential homes with care services for the elderly in Tokyo and Kanagawa. When focusing on physical functions, the Alb level was higher among residents exhibiting higher total ADL20 scores; based on this, approaches to prevent decreases in the nutritional status may be essential for the maintenance of ADL independence. This tendency was particularly marked when examining scores from the following ADL20 subscales: <indoor walking>, <ascending/descending stairs>, and $<$ outdoor walking>, as the Alb level was higher among those who were able to perform these activities more independently. Regarding cognitive functions, the Alb level was lower when the total CDR score and scores from the following subscales indicated higher severity: <memory >, <orientation>, <judgment >, < social adaptation>, <family situation>, and <care situation>. This highlights the necessity of continuous nutritional management as a preventive measure against dementia. This study is suggesting the necessity of performing nutritional management, such as maintaining and restoring a favorable nutritional status in residential homes for the elderly lead a healthy and mentally and physically independent life.
\end{abstract}

Received

December 12, 2016

Revised

February 23, 2017

Accepted

February 25, 2017

Published

April 30, 2017
$<$ Key-words $>^{-}$

nutritional status, mental/physical functions, residential homes for the elderly

yfujio@juntendo.ac.jp (Yuko FUJIO; Japan)

Asian J Human Services, 2017, 12:1-7. @ 2017 Asian Society of Human Services 


\section{Introduction}

In Japan, residential homes with and without care services are currently available as private homes for the elderly. When using home care services based on the Long-term Care Insurance System, subsidies are allocated, corresponding to the category 'daily care for specific facility users'. In recent years, while delays in the construction of Long-term Care Insurance-covered facilities have been noted, the numbers of private (residential) homes for the elderly and their residents have steadily increased; the values, which were 276 and 30,792 , respectively, in 2008, increased to 7,563 and 315,678, respectively, in 2013. On comparing the national mean Care Grade and that of insurance-covered facility users, the former is still lower, at 2.2, but grades 4 and 5 account for more than $25 \%$, revealing the increasing demand of the elderly requiring care for such homes.

Residential homes for the elderly are regarded as new locations for the elderly to relocate from their long-lived-in homes (Toyama, 2014). Furthermore, it is expected that the homes will accommodate needs related to the comprehensive community-based care system as key to social insurance system reform to prepare for 2025, when all baby-boomers will be aged 75 or over. In such a situation, care approaches in these homes should be reviewed, covering the concept of 'private but unaccustomed homes, in addition to that of 'facilities'. Although some studies examined multi-professional collaboration in residential homes with care services for the elderly, involving their staff (Kakinuma, 2013), the actual situation of such homes with or without care services, including residents' conditions and the contents of care, has yet to be clarified. Furthermore, as the mean Care Grade on admission to residential homes for the elderly is lower than that in insurance-covered facilities, the length of residence in the former tends to be long, and a large number of the elderly chose to stay in such homes until the end of their lives. In line with this, care for residents showing steadily progressing age-related changes in their conditions, leading to the necessity of leading a daily life in the presence of multiple diseases occurring with time, or coping with cognitive impairment, is needed in these homes.

Malnutrition is regarded as a leading cause of the progression of care dependency. When the Long-Term Care Insurance Act was revised, nutritional management was added as a category of business activities to prevent care-dependency. According to an estimate based on the results of comprehensive evaluation of the outcomes of such activities (Tsuji, Ueda, Okubo et al., 2009) approximately 30\% of elderly individuals with an increased risk of care-dependency require nutritional improvement.

To examine the nutritional status and mental/physical functions of care-dependent individuals living in residential homes with care services for the elderly, focusing on the former as a factor associated with care dependency and its progression, and to clarify the association between the former and latter. 


\section{Methods}

\section{Study design}

A quantitative, descriptive study (status survey)

\section{Study period}

November 2015 (30 days)

\section{Subjects}

Care-dependent individuals living in residential homes with care services for the elderly

\section{Study items}

1) Basic attributes : Sex , Age

2) Care grade

3) Nutritional status : dietary intake, albumin (Alb) level

4) Physical functions : Levels of ADL Independence of the Elderly with Disabilities ( $\mathrm{J}$ : outdoor walking level , A : indoor walking level , B : wheelchair level, C : bed level, ADL20 (Activities of Daily Living 20)

5) Mental functions : Levels of ADL Independence of the Elderly with Dementia ( I : suspect level, II : attention level, III: sometimes care level, IV: all day care level, M : hospital level ), CDR (Clinical Dementia Rating, CDR0.5 : suspected dementia , CDR1 : mild dementia , CDR2 : moderate dementia, CDR3 : severe dementia )

6) Status of hospital visits

\section{Data collection}

A questionnaire survey was conducted, asking home staff to provide copies of data related to residents.

\section{Data analysis}

The associations among the nutritional status and mental/physical functions of care-dependent residents were analyzed using SPSS Ver.22.0 as statistical analysis software.

\section{Ethical considerations}

This study was conducted with the approval of the Ethics Committee of the Faculty of Health Care and Nursing, Juntendo University. Questionnaire responses were transcribed by home staff. In the process of transcription, the data were converted into IDs as a measure to prevent the identification of individuals. 


\section{Results}

Data related to 147 care-dependent individuals living in 3 residential homes with care services for the elderly in Tokyo and Kanagawa. There were 28 (19.0\%) males and 119 $(81.0 \%)$ females, with a mean age of $88.7 \pm 5.5$. Their mean Care Grade was $3.13 \pm 1.64$. The mean dietary intakes were $1230.0 \pm 304.4 \mathrm{kcal}$. The mean Alb levels were $3.6 \pm 0.5 \mathrm{~g} / \mathrm{dl}$. Ranks based on the Degrees of ADL Independence of the Elderly with Disabilities varied as follows: J: 6(4\%), A: 74(50\%), B: 51(35\%), and C: 16(11\%). The mean ADL20 score was $20.5 \pm 15.9 / 80$, revealing their poor ADL independence. The results of the Degrees of ADL Independence of the Elderly with Dementia were as follows: I: 21(14\%), IIa: 29(20\%), IIb: 37(25\%), IIIa: 21(14\%),IV:16 (11\%),M:4(3\%). On assessment using the CDR, $24 \%$ of all cases were classified as mild (CDR-1) and severe (CDR-3) dementia, followed by suspected (CDR-0.5; 23\%) and moderate (CDR-2; 20\%) dementia; all severities of dementia were similarly observed (Table 1 ).

<Table 1> Basic Attributes of Care-dependent Elderly (n=147)

\begin{tabular}{lrr}
\hline Sex & $\begin{array}{c}\text { Males } \\
\text { Females }\end{array}$ & $28(19 \%)$ \\
\hline Age & & $119(81 \%)$ \\
\hline Care grade & & $88.7 \pm 5.5$ \\
\hline Dietary intakes & & $3.13 \pm 1.64$ \\
\hline Alb levels & $\mathrm{J}$ & $3.6 \pm 0.5 \mathrm{~g} / \mathrm{dl}$ \\
\hline & $\mathrm{A}$ & $6(4 \%)$ \\
Levels of ADL Independence of the & $\mathrm{B}$ & $74(50 \%)$ \\
Elderly with Disabilities & $\mathrm{C}$ & $51(35 \%)$ \\
& & $16(11 \%)$ \\
\hline ADL20 score & $\mathrm{I}$ & $20.5 \pm 15.9 / 80$ \\
\hline & $\mathrm{II}$ & $21(14 \%)$ \\
& $\mathrm{a}$ b & $29(20 \%)$ \\
Levels of ADL Independence of the & III a & $37(25 \%)$ \\
Elderly with Dementia & IIb & $21(14 \%)$ \\
& $\mathrm{IV}$ & $19(13 \%)$ \\
& $\mathrm{M}$ & $16(11 \%)$ \\
& $\mathrm{CDR}-0.5$ & $4(3 \%)$ \\
\hline & $\mathrm{CDR}-1$ & $34(23 \%)$ \\
CDR & $\mathrm{CDR}-2$ & $35(24 \%)$ \\
& $\mathrm{CDR}-3$ & $29(20 \%)$ \\
& & $34(23 \%)$ \\
\hline
\end{tabular}


On correlation analysis, the Alb level, representing the nutritional status, showed a weak negative correlation with the age $(-.226)$ as an attribute. Regarding physical functions, the Alb level also showed a weak negative correlation with the results of the Degrees of ADL Independence of the Elderly with Disabilities (-.223) , and a weak positive correlation with the total ADL20 score (.239) and scores from the following subscales: <indoor walking (.233) >, < ascending/descending stairs (.227) > , and <outdoor walking $(.214)>$. Regarding cognitive functions, the Alb level showed a weak negative correlation with the results of the Degrees of ADL Independence of the Elderly with Dementia $(-.240)$, in addition to the total CDR score $(-.252)$ and scores from the following subscales: <memory $(-.280)>$, <orientation $(-.209)>$, <judgment $(-.246)>$, < social adaptation $(-.245)>$, < family situation $(-.284)>$, and $<$ care situation $(-.321)>$. It showed a weak positive correlation with the status of hospital visits (.254) (Spearman's $\rho$ ). These results are shown in Table 2 .

<Table 2> Correlations among the Alb Level and Mental/Physical Functions (n=147)

\begin{tabular}{|c|c|c|}
\hline & & Alb level \\
\hline Attributes & Age & $-.266^{* *}$ \\
\hline \multirow{5}{*}{ Physical functions } & $\begin{array}{r}\text { Results of the Degrees of ADL Independence of } \\
\text { the Elderly with Disabilities }\end{array}$ & $-.223^{* * *}$ \\
\hline & ADL20 <indoor walking $>$ & $.233^{* *}$ \\
\hline & ADL20 < ascending/descending stairs $>$ & $.227^{* *}$ \\
\hline & ADL20 < outdoor walking > & $.214^{* *}$ \\
\hline & Total ADL20 score & $.239^{* *}$ \\
\hline \multirow{8}{*}{$\begin{array}{l}\text { Cognitive } \\
\text { functions }\end{array}$} & $\begin{array}{r}\text { Results of the Degrees of ADL Independence of } \\
\text { the Elderly with Dementia }\end{array}$ & $-.240^{* *}$ \\
\hline & CDR $<$ memory $>$ & $-.280^{* *}$ \\
\hline & $\mathrm{CDR}<$ orientation $>$ & $-.209^{*}$ \\
\hline & CDR <judgment $>$ & $-.246^{* *}$ \\
\hline & CDR $<$ social adaptation $>$ & $-.245^{* *}$ \\
\hline & $\mathrm{CDR}<$ family situation $>$ & $-.284^{* *}$ \\
\hline & CDR $<$ care situation $>$ & $-.321^{* *}$ \\
\hline & Total CDR score & $-.252^{* *}$ \\
\hline Others & Status of hospital visits & $.254^{* * *}$ \\
\hline
\end{tabular}

Furthermore, to clarify factors influencing the Alb level, multiple regression analysis (stepwise method) was performed with the Alb level as a dependent variable and the items that showed a correlation on correlation analysis as independent variables. Among the CDR and ADL 20 items, <memory (-.216) > and <indoor walking (.177) >, respectively, were shown to influence the Alb level. The obtained regression equation was as follows:

The Alb level $=-0.074 \times$ CDR: $<$ memory $>+0.066 \times$ ADL20: $<$ indoor walking $>+3.715$ 
$<$ Table 3> Results of Multiple Regression Analysis of the Alb Level and Mental/Physical Functions ( $\mathrm{n}=147)$

\begin{tabular}{|c|c|}
\hline & Standardizing coefficient \\
\hline CDR: <memory $>$ & $-.216^{*}$ \\
\hline ADL20: <indoor walking> & $.177^{*}$ \\
\hline $\mathrm{R}^{2}$ & .102 \\
\hline Adjusted $\mathrm{R}^{2}$ & .089 \\
\hline F-value & $8.080^{* *}$ \\
\hline $\mathrm{df}$ & 2 \\
\hline
\end{tabular}

$* \mathrm{p}<0.05 \quad * * \mathrm{p}<0.01$

Stepwise method

\section{Discussion}

On analyzing the associations among the nutritional status and mental/physical functions of care-dependent individuals living in residential homes for the elderly, with the Alb level as an index for the former, the level was lower among older residents, indicating the necessity of continuous nutritional management for individuals living for a long period in residential homes for the elderly.

When focusing on physical functions, the Alb level was higher among residents exhibiting higher total ADL20 scores; based on this, approaches to prevent decreases in the nutritional status may be essential for the maintenance of ADL independence. This tendency was particularly marked when examining scores from the following ADL20 subscales: <indoor walking>, <ascending/descending stairs>, and <outdoor walking>, as the Alb level was higher among those who were able to perform these activities more independently. This is consistent with the results of the researchers' previous study, in which the mobility and walking ability were suggested to influence the Alb level (Fujio, Ogawa, Inoue et al., 2016).

Regarding cognitive functions, the Alb level was lower when the total CDR score and scores from the following subscales indicated higher severity: <memory $>$, <orientation>, $<$ judgment $>$, <social adaptation $>$, <family situation $>$, and $<$ care situation $>$. This highlights the necessity of continuous nutritional management as a preventive measure against dementia. Approaches for appropriate hydration, nutrition, activities, and bowel movements have also been shown to be important as a part of basic care for individuals with dementia; in a study, symptoms of dementia markedly improved through workshops for the families of patients with dementia, adopting such basic care approaches (Kodaira \& Takeuchi, 2015).

It was also revealed that residents with lower Alb levels visited hospitals more regularly, indicating the presence of some disease. 
In the researchers' previous study, both medical and welfare service providers' awareness of care-dependent individuals' nutritional status was poor (Fujio \& Kodaira, 2014), indicating the necessity of nutritional management may be indispensable.

\section{Conclusion}

This study is suggesting the necessity of performing nutritional management, such as maintaining and restoring a favorable nutritional status in residential homes for the elderly lead a healthy and mentally and physically independent life.

\section{References}

1) Tadashi TOYAMA (2014) Private but Unfamiliar Homes - Theory of Living Spaces for the Elderly -. Igaku-Shoin Ltd.

2) Tomohiro KAKINUMA (2013-2014) A Report on the Evaluation of Multi-professional Collaboration in Residential Homes with Care Services for the Elderly. FY 2013 - FY 2014 Grants-in-Aid for Scientific Research (multi-year fund), Grant-in-Aid for Young Scientists (B)

3) Ichiro TSUJI, Koichiro UEDA, Ichiro OKUBO, Yutaka ONO, Satoko OHARA, Shuichi OBUCHI et al. (2009) Comprehensive assessment and analysis of the effects of the Projects to Prevent the Need for Care. A Grant-in-Aid for Health Care Promotion Services for the Elderly (Promotion of Health and Health Care for the Elderly).

4) Yuko FUJIO, Noriko OGAWA, Yoshiyuki INOUE \& Takahito TAKEUCHI (2016) Indices of Undernutrition in the Care-dependent Elderly, Asian Journal of Human Services, 10,16-24.

5) Megumi KODAIRA \& Takahito TAKEUCHI (2015) Provision of a family-care seminar for 64 demented individuals using Takeuchi's theory: A family-led dementia-alleviation program, Asian Journal of Human Service, 9, 1-16.

6) Yuko FUJIO \& Megumi KODAIRA (2014) Care Service Staff's Awareness of the Management of Undernutrition in Japan, Asian Journal of Human Services, 7, $51-59$. 
Asian Society of HUMAN SERVICES

- Editorial Board -

Editor-in-Chief
Executive Editors

Masahiro KOHZUKI
Injae LEE
Satoru EBIHARA

Tohoku University (Japan)

Hanshin Univerisity (Korea)

Toho University (Japan)

Atsushi TANAKA
University of the Ryukyus (Japan)
Changwan HAN
University of the Ryukyus (Japan)
Guo QI
Tianjin Medical University (China)
Hideyuki OKUZUMI
Tokyo Gakugei University (Japan)
Hsintai LIN
National Taiwan Noraml University (Taiwan)
Inkeri Ruokonen
University of Helsinki (Finland)
Jaewon LEE
Pukyong National University (Korea)
Jenyi LI
Nanyang Technological University (Singapore)
Jung Won Sonn
University College London (UK)

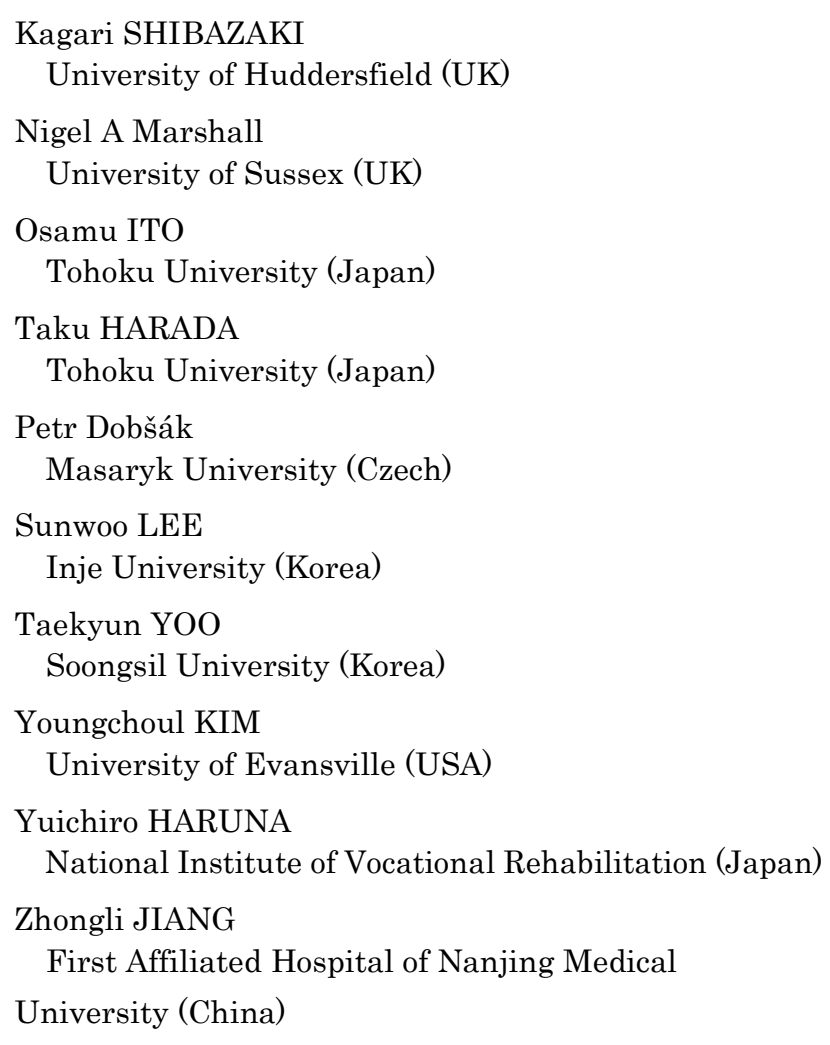

Editorial Staff

$\begin{array}{lll}\text { - Editorial Assistants } & \text { Aiko KOHARA } & \text { University of the Ryukyus (Japan) } \\ & \text { Marcus Eije Zantere } & \text { University of Gothenburg (Sweden) } \\ & \text { Moonjung KIM } & \text { Ewha Womans University (Korea) } \\ & \text { Natsuki YANO } & \text { Tohoku University (Japan) }\end{array}$

\section{Asian Journal of Human Services VOL.12 April 2017}

(C) 2017 Asian Society of Human Services

Editor-in-Chief Masahiro KOHZUKI

Presidents Masahiro KOHZUKI - Sunwoo LEE

Publisher Asian Society of Human Services

Faculty of Education, University of the Ryukyus, 1 Senbaru, Nishihara, Nakagami, Okinawa, Japan FAX: +81-098-895-8420 E-mail: ashs201091@ gmail.com

Production 
Asian Journal of Human Services

VOL.12 April 2017

CONTENTS

\section{ORIGINAL ARTICLES}

Associations among the Nutrional Status and Mental/Physical Functions of Care-dependent Individuals Living in Residential Homes for the Elderly

Yuko FUJIO, et al. 1

A Survey on International Nursing Education of National Universies in Japan

Akina ISHIBASHI, et al. 8

Academic Qualification and Job Market Placement: A Bangladesh Study

Rajib Ahmed FAISAL, 17

The Influence of Living Environment on Independence level of Special Nursing Home

Yukie ENOMOTO, et al. 30

Encouraging Exercise Participation amongst UK South Asians:

The Case of a Community Gym

Nigel KING, et al. 46

Promoting Wellbeing:

Amylase as an Indication of Changes in Stress level in People with Intellectual Disabilities

Nigel A. MARSHALL, et al. 60

Published by

Asian Society of Human Services

Okinawa, Japan 